\title{
ANALISA PERSEDIAAN MATERIAL PADA FIRE TUBE BOILER STOCK YANG OPTIMAL DENGAN MENGGUNAKAN MARKOV CHAIN
}

\author{
Titik Noorida*)
}

\section{ABSTRACT}

Controlling material stock becomes important problem that faced by the company because controlling it supports production process continually. In applaying material is efforted in order getting cost of supplier more law as possible.

PT. Indomarine is one kind of company that produces tube involving two type are fire tube and water tube, in which the primary material is tube and plat. In dealing the consumen needs, the company should give amount materials so that the production will be continually, and the consumer will satisfy. Having more suplies like that is caused by accepting fluctually needs, than causes less supplier optimumly and less in cost too. Based on fenomenon above, so in this research will mucstigate the methods that will be counted the number of material asking.

To determine the number of material needs decisionand to determine the cost of optimumly material, this research uses the Markov Chains method.

By using Markov Chain method so the data from the company will be analys. The result of analysis will be placed optimumly tube material in second iteration $\mathrm{x}_{0}=613, \mathrm{x}_{82}=531, \mathrm{x}_{164}=449, \mathrm{x}_{328}=$ $285, x_{410}=203$.

By having optimumly stock, so will be optimum cost too $\mathrm{f}_{0}=\mathrm{Rp} 555.772 .160, \mathrm{f}_{82}=\mathrm{Rp} 557.532 .698, \mathrm{f}_{164}$ $=\operatorname{Rp} 559.293 .236, \mathrm{f}_{246}=\operatorname{Rp} 561.053 .775, \mathrm{f}_{328}=\operatorname{Rp} 585.438 .154, \mathrm{f}_{410}=\operatorname{Rp} 564.574 .852$.

For that material in the second iteration that is $X_{0}=21, X_{3}=18, X_{6}=15, X_{9}=12, X_{12}=9, X_{15}=6$.

By having optimum stock, so if will be achieving the optimum cost toof $f_{0}=R p 372.985 .280, f_{3}=R p$ 373.044.382, $\mathrm{f}_{6}=\operatorname{Rp} 373.103 .192, \mathrm{f}_{9}=\operatorname{Rp} 373.162 .148, \mathrm{f}_{12}=\operatorname{Rp} 373.221 .104, \mathrm{f}_{15}=\operatorname{Rp} 373.280 .060$.

Key words: Markov Chain, Stock, Material

\section{A. PENDAHULUAN}

Persediaan bahan baku di dalam perusahaan "adalah merupakan hal yang sangat wajar untuk dikendalikan dengan baik. Setiap perusahaan yang menghasilkan produk (perusahaan-perusahaan yang menghasilkan produk) akan memerlukan persediaan bahan baku ini. Baik disengaja ataupun tidak perusahaan yang bersangkutan ini akan menyelenggarakan persediaan bahan baku yang menunjang jalannya proses produksi. Dalam penyelenggaraan persediaan bahan baku ini akan diusahakan agar bahan baku yang ada di dalam perusahaan akan dapat mempunyai biaya persediaan yang serendah mungkin.

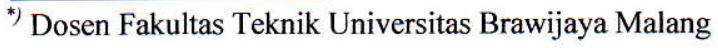

PT. INDOMARINE adalah perusahaan yang memproduksi ketel uap dengan dua tipe yaitu fire tube dan water tube, dimana bahan baku utama adalah plat dan pipa. Pada kenyataannya pesanan yang datang pada PT. INDOMARINE lebih banyak fire tube dibandingkan dengan water tube, sehingga menyebabkan kebutuhan bahan baku dari fire tube meningkat pula. Salah satu perioritas perbaikan pada PT. INDOMARINE adalah tingkat persediaan bahan baku yang kurang mengenai kriteria untuk menjamin kelancaran proses produksi, artinya persediaan bahan baku sering kurang atau lebih dadaripada kapasitas 
produksi. Kekurangan bahan bahan baku dalam perusahaan ini akan mengakibatkan terhentinya pelaksanaan proses produksi. Dilain pihak persediaan bahan baku yang cukup besar dalam perusahaan ini juga akan membawa berbagai macam akibat yang akan merugikan perusahaan pula. Persediaan yang diselenggarakan dalam jumlah besar mengakibatkan terjadinya biaya-biaya persediaan bahan baku menjadi besar pula. Besarnya biaya-biaya persediaan dapat mengurangi keuntungan yang seharusnya bisa dicapai oleh perusahaan. Disamping itu resiko kerusakan bahan baku juga semakin tinggi, sehingga mutu dari plat dan pipa akan berkurang apabila disimpan terlalu lama. Keadaan tersebut tentunya mengakibatkan berkurangnya keuntungan yang diperoleh perusahaan. Selain itu juga menyebabkan kehilangan pelanggan karena ketidakmampuan perusahaan menyediakan kebutuhan pelanggan tepat pada waktunya.

\section{Tujuan}

Adapun tujuan untuk memecahkan permasalahan ini adalah sebagai berikut

1. Menentukan kebijakan persediaan bahan baku yang optimal.

2. Menentukan biaya perencanaan persediaan bahan baku yang optimal.

\section{B. LANDASAN TEORI}

\section{Pengertian pengendalian persediaan}

Persediaan adalah merupakan salah satu unsur yang paling aktif dalam operasi perusahan yang secara kontinyu diperoleh, diubah, yang kemudian dijual kembali (Assauri, 1993: 220).

Jadi, pengertian dari pengendalian persediaan dapat dikatakan suatu kegiatan untuk menentukan tingkat dan komposisi pengaturan dan pengawasan atas pelaksanaan pengadaan bahan yang diperlukan sehingga sesuai dengan yang dibutuhkan dan biaya yang serendah-rendahnya agar perusahaan dapat melindungi kelancaran produksi dan penjualan serta kebutuhankebutuhan pembelanjaan perusahaan.

\section{Biaya-biaya Dalam Persediaan}

Biaya-biaya yang timbul dari adanya persediaan (Assauri,1993:225), antara lain:

a. Biaya pemesanan (ordering costs).

b. Biaya yang terjadi dari adanya persediaan (inventory carrying costs).

a. Biaya kekurangan persediaan (out of stock costs)

d. Biaya-biaya yang berhubungan dengan kapasitas (capacity associated costs)

\section{Definisi Proses Markov}

Proses Markov (Taha,1997:344) adalah sebuah sistem stokhastik yang untuknya permunculan sesuatu keadaaan di masa mendatang bergantung pada keadaan yang segera mendahuluinya dan hanyalah bergantung pada itu.

\section{Proses Keputusan Markov Chain}

Jika tingkat persediaan diperiksa tiap minggu, kemudian menentukan persediaan maksimum, tentukan pada alternatif pada tingkat pemesanan $\mathrm{x}$. Nilai $\mathrm{x}$ merupakan strategi yang memuaskan tiap nilai dari state variable dan tentukan pula Policy (strategi) yangmungkin secara sembarang

Langkah-langkah pemecahan dan
penentuan ruang policy.


1. Policy awal

2. Evaluasi Policy Rutin

3. Perbaikan Policy Rutin

4. Aturan Berhenti

\section{METODE}

Untuk menyelesaikan permasalahan tersebut diperlukan data yang berhubungan dengan permasalahan yang ada untuk memperoleh data tersebut. Adapun langkah-langkah untuk menyelesaikan penelitian tersebut yaitu:

1. Survey Perusahaan

Survey perusahaan dilakukan untuk mendapatkan gambaran awal mengenai permasalahan apa yang dapat diangkat untuk mengadakan penelitian.

\section{Studi Literatur}

Studi literature dilakukan untuk mendukung dalam menyelesaikan permasalahan.

\section{Identifikasi Masalah}

Identifikasi masalah dilakukan untuk mengenal sekaligus merumuskan permasalahan yang ada pada waktu survey.

\section{Pengumpulan Data}

Data-data yang diperlukan antara lain: data permintaan bahan baku,

harga bahan baku, biaya penyimpanan, biaya pemesanan.

\section{Pengolahan Data}

Data-data yang terkumpul kemudian diolah untuk mencari data persediaan awal, probabilitas serta biaya kekurangan persediaan.

\section{Analisa Data}

Analisa data dengan menggunakan perencanaan pengendalian persediaan dengan mettode markov chain tahap tak hingga metode iterasi dengan discount.

\section{Kesimpulan}

Penarikan kesimpulan dari hasil pengolahan serta analisis data yaitu persediaan bahan baku yang optimal serta biaya persediaan yang optimal.

\section{ANALISA}

PT. INDOMARINE adalah perusahaan yang memproduksi ketel uap dengan dua tipe yaitu fire tube dan water tube, dimana bahan baku utama adalah plat dan pipa.

Salah satu perioritas perbaikan pada PT. INDOMARINE adalah tingkat persediaan bahan baku yang kurang mengenai kriteria untuk menjamin kelancaran proses produksi, artinya persediaan bahan baku sering kurang atau lebih dadaripada kapasitas produksi. Kekurangan bahan bahan baku dalam perusahaan ini akan mengakibatkan terhentinya pelaksanaan proses produksi.

\section{Data Material}

Jenis material yang dipakai dalam studi ini adalah material kelompok pipa dan plat. Dimana pipa yang digunakan adalah pipa dengan ukuran $\emptyset 63.5 \mathrm{~mm}$, tebal $3.2 \mathrm{~mm}$ dan panjang $7 \mathrm{~m}$ sedangkan plat dengan ukuran $(0,016 \times 4.502 \times 7.154)$ dalam $\mathrm{m}$.

\section{Data Pemakaian}

Data pemakaian material tiap bulan pada tahun 1995-2001 dapat dilihat dari data permintaan produk sebagai berikut : 


\section{Tabel 1}

Pemakaian Pipa Dan Plat Tiap 4 Bulan

\begin{tabular}{|l|c|c|}
\hline \multicolumn{1}{|c|}{ PERIODE } & $\begin{array}{c}\text { PIPA } \\
\text { (pcs) }\end{array}$ & $\begin{array}{c}\text { PLAT } \\
\text { (pcs) }\end{array}$ \\
\hline Jan 95-Apr 95 & 366 & 12 \\
\hline Mei 95-Agt 95 & 610 & 20 \\
\hline Sep 95-Des 95 & 122 & 4 \\
\hline Jan 96-Apr 96 & 122 & 4 \\
\hline Mei 96-Agt 96 & 366 & 12 \\
\hline Sep 96-Des 96 & 366 & 12 \\
\hline Jan 97-Apr 97 & 122 & 4 \\
\hline Mei 97-Agt 97 & 122 & 4 \\
\hline Sep 97-Des 97 & 244 & 8 \\
\hline Jan 98-Apr 98 & 488 & 16 \\
\hline Mei 98-Agt 98 & 122 & 4 \\
\hline Sep 98-Des 98 & 244 & 8 \\
\hline Jan 99-Apr 99 & 122 & 4 \\
\hline Mei 99-Agt 99 & 122 & 4 \\
\hline Sep 99-Des 99 & 122 & 4 \\
\hline Jan 00-Apr 00 & 366 & 12 \\
\hline Mei 00-Agt 00 & 122 & 4 \\
\hline Sep 00-Des 00 & 244 & 8 \\
\hline Jan 01 - Apr 01 & 244 & 8 \\
\hline Mei 01 - Agt 01 & 122 & 4 \\
\hline Sep 01 - Des 01 & 366 & 12 \\
\hline
\end{tabular}

\section{Data Biaya-Biaya}

Biaya-biaya yang timbul dari adanya persediaan (Assauri,1993:225), antara lain:

a. Biaya pemesanan (ordering costs).

b. Biaya yang terjadi dari adanya persediaan (inventory carrying costs).

c. Biaya kekurangan persediaan (out of stock costs)

d. Biaya-biaya yang berhubungan dengan kapasitas (capacity associated costs

Data biaya yang digunakan diambil suatu biaya pada salah satu tahun pengambilan data yaitu tahun 2001:

1. Biaya pesan ditetapkan oleh team yaitu sebesar Rp 6.400.000,-/pesan, ini diperoleh dengan memberi biaya operasi team dengan jumlah pesan yang dikeluarkan selama setahun.

2. Biaya simpan material pertahun dinyatakan dengan prosentase nilai material yang disimpan, yaitu:

a. Biaya kapital pertahun $15 \%$

b. Biaya gudang diperoleh dari hasil bagi biaya operasi rata-rata setahun sebesar Rp 72.500.000,- dengan persediaan rata-rata sebesar $\mathrm{Rp}$ 6.000.000.000,maka biaya gudang sebesar $1,2 \%$.

c. Biaya kehilangan sebesar 0 karena tidak pernah terjadi kehilangan material di gudang.

d. Biaya keusangan untuk material sebesar $0,075 \%$ yang diperoleh dari rata-rata material yang tidak layak pakai setelah disimpan selama 1 tahun di gudang.

Jadi total biaya simpan :

$$
\begin{aligned}
& 15 \%+1,2 \%+0+0,075 \% \\
& =16,275 \% \text { per tahun } \\
& =5,425 \% \text { per } 4 \text { bulan. }
\end{aligned}
$$

\section{Menentukan Optimum Persediaan dan}

\section{Total Cost}

Dari data-data diatas dapat disimpulkan bahwa:

- Pemakaian bahan baku plat dan pipa merupakan kejadian yang tidak pasti.

Berdasarkan kesimpulan diatas serta studi pustaka pada bab 2 maka dapat dibuat model persediaan untuk jangka waktu 
Optimum, Volume 4, Nomor 1, Februari -Agustus 2003:40 -49

lama atau tak terbatas dengan menggunakan rantai Markov.

Sedangkan biaya-biaya yang berhubungan dengan persediaan bahan baku adalah:

- Bunga Bank yang berlaku $=12 \%$ per tahun.

- $\quad$ Harga bahan baku pipa $=\mathrm{Rp} 12.000,-$ per $\mathrm{Kg}$, plat

$$
=\operatorname{Rp} 9.000 \text {,- per } \mathrm{Kg}
$$

- 1 pcs pipa $=32,98 \mathrm{Kg}, 1$ pcs plat $=40,35 \mathrm{Kg}$

- Biaya penyimpanan per unit per 4 bulan $=5,425$ $\%$ (harga mat $\mathrm{x}$ jumlah mat)

Untuk pipa

$=5,425 \% \times 12.000 \times 32,98 \times$ state $\mathrm{i}$

Untuk plat

$$
=5,425 \% \times 9.000 \times 40,35 \times \text { state } \mathrm{i}
$$

- Biaya kekurangan persediaan

$=\operatorname{Rp} 6.400 .000+($ harga mat $x$ jumlah mat)

Untuk pipa

$=\operatorname{Rp} 6.400 .000,-+(12.000 \times 32,98 \times 122)$

Untuk plat

$=\operatorname{Rp} 6.400 .000,-+(9.000 \times 40,35 \times 4)$

\section{Bahan Baku Pipa}

Untuk menentukan probabilitas pemakaian berdasarkan frekuensi relatif. Misalnya sebuah peristiwa $\mathrm{E}$ dapat terjadi sebanyak n kali diantara $\mathrm{N}$ peristiwa yang saling exlusive dan masing-masing terjadi dengan kesempatan yang sama. Maka peluang peristiwa $\mathrm{E}$ yang terjadi adalah $\mathrm{n} / \mathrm{N}$ dan dituliskan dalam bentuk $\mathrm{P}(\mathrm{E})=\mathrm{n} / \mathrm{N}$ (Sudjana,1996: 114).

Probabilitas pemakaian untuk 122-203 pcs $=10 / 21=$ 0.47

Berdasarkan data-data pada tabel 4.2 maka distribusi frekuensi pemakaiannya adalah sebagai berikut:

Data terbesar - data terkecil $=610-122$

$$
=488
$$

$$
\begin{aligned}
\text { Range } & =1+3,3 \log n \\
& =1+3,3 \log 21 \\
& =5,36 \approx 6
\end{aligned}
$$

Interval $=488 / 6$

$$
=81,33 \approx 82
$$

Tabel 2

Probabilitas Pipa Tiap 4 Bulan

\begin{tabular}{|c|c|c|}
\hline $\begin{array}{c}\text { Pemakaia } \\
\text { n }\end{array}$ & Frek & Probabilitas \\
\hline $122-203$ & 10 & 0,47 \\
\hline $204-285$ & 4 & 0,19 \\
\hline $286-367$ & 5 & 0,24 \\
\hline $268-449$ & 0 & 0 \\
\hline $450-531$ & 1 & 0,05 \\
\hline $532-613$ & 1 & 0,05 \\
\hline Jumlah & 21 & 1 \\
\hline
\end{tabular}

Kemudian kita dapat menentukan persediaan awal dengan asumsi bahwa persediaan awal (state i) adalah 0, 82, 164, 246, 328, 410 (dalam pes). Kemudian menentukan strategi yang memuaskan atau persediaan policy untuk menambahkan persediaan yaitu nilai dari $\mathrm{R}$ untuk tiap nilai variabel tetap.

Tabel 3

Tingkat Persediaan Awal dan Penambahan Persediaan

\begin{tabular}{|c|c|c|c|c|c|c|}
\hline $\begin{array}{c}\text { State } \\
\text { i }\end{array}$ & \multicolumn{6}{|c|}{ Pemilihan Untuk Tingkat } \\
& \multicolumn{6}{|c|}{ Pemesanan (x) } \\
\hline $\mathbf{0}$ & 203 & 285 & 367 & 449 & 531 & 613 \\
\hline $\mathbf{8 2}$ & 203 & 285 & 367 & 449 & 531 & \\
\hline $\mathbf{1 6 4}$ & 203 & 285 & 367 & 449 & & \\
\hline $\mathbf{2 4 6}$ & 203 & 285 & 367 & & & \\
\hline $\mathbf{3 2 8}$ & 203 & 285 & & & & \\
\hline $\mathbf{4 1 0}$ & 203 & & & & & \\
\hline
\end{tabular}


Berdasarkan ketetapan Markov Chain bahwa pemberian putusan $x$, suatu state dari sistem mengalami transisi dari state $\mathrm{i}$ ke state $\mathrm{j}=\mathrm{i}+\mathrm{x}-$ d dengan probabilitas $\mathrm{Pij}(\mathrm{x})=\mathrm{P}(\mathrm{d})$.

\section{Keterangan:}

$\begin{array}{ll}\text { State } \mathrm{i} & =\text { Persediaan awal } \\ \text { Putusan } \mathrm{x} & =\text { Tingkat Pemesanan } \\ \mathrm{d} & =\text { Demand } \\ \mathrm{A} & =\text { Biaya Pemesanan } \\ \mathrm{B} & =\text { Biaya Penyimpanan } \\ & =5,425 \% \mathrm{x} \text { (harga material } \mathrm{x} \text { jumlah } \\ \mathrm{E} & \text { material) } \\ \mathrm{Ci}(\mathrm{x}) & =\text { Shortage Cost }\end{array}$

Untuk menentukan tingkat probabilitas transisi, harus melihat tabel 4.3 dan 4.4, sehingga dapat ditentukan sebagai berikut:

Untuk $\mathrm{i}=0 ; \mathrm{x}=203$

$$
\begin{aligned}
& \text { Jika } \mathrm{j}=0 \\
& \text { Maka } \mathrm{j}=\mathrm{i}+\mathrm{x}-\mathrm{d} \\
& \qquad \begin{aligned}
& 0=0+203-\mathrm{d} \Rightarrow \mathrm{d}=203 \\
& \text { Probabilitas Pij }= \mathrm{P}_{0,0}(203) \\
&=P(\mathrm{~d} \geq 203) \\
&=1
\end{aligned}
\end{aligned}
$$

Untuk probabilitas lainnya $=0$

Shortage Cost $=$ Rp 6.400.000,-

$$
\begin{aligned}
+ & \mathrm{Rp} 48.282 .720,-\left[\sum_{d>i+x}(d-i-X) P(d)\right] \\
= & \mathrm{Rp} \mathrm{6.400.000,-}+\mathrm{Rp} 48.282 .720,-[(285-203) 0,19+ \\
& (367-03) 0,24+(449-203) 0+(531-203) 0,05+ \\
& (613-203) 0,05 \\
= & \operatorname{Rp~} 4.440 .685 .005,-
\end{aligned}
$$

Selanjutnya dicari probabilitas transisi untuk semua baris, maka dapat diketahui:

Langkah 1: Berdasarkan tabel 4.5 maka dapat ditentukan probabilitas transisi, putusan dan biaya.

Probabilitas Transisi:

$$
\begin{array}{llllll}
0.05 & 0.05 & 0 & 0.24 & 0.19 & 0.47 \\
0.05 & 0.05 & 0 & 0.24 & 0.19 & 0.47 \\
0.05 & 0.05 & 0 & 0.24 & 0.19 & 0.47 \\
0.05 & 0.05 & 0 & 0.24 & 0.19 & 0.47 \\
0.05 & 0.05 & 0 & 0.24 & 0.19 & 0.47 \\
0.05 & 0.05 & 0 & 0.24 & 0.19 & 0.47
\end{array}
$$

Putusan:

$$
\begin{array}{ll}
\mathrm{C}_{0} & =613 \\
\mathrm{C}_{82} & =531 \\
\mathrm{C}_{164} & =449 \\
\mathrm{C}_{246} & =367 \\
\mathrm{C}_{328} & =285 \\
\mathrm{C}_{410} & =203
\end{array}
$$

Biaya:

12.800 .000

14.560 .538

16.321 .076

18.081.615

19.842.153

21.602 .692

Policy awal: $\quad \mathrm{x}_{0}{ }^{(0)}=613$

$$
\begin{aligned}
& \mathrm{x}_{82}{ }^{(0)}=531 \\
& \mathrm{x}_{164}{ }^{(0)}=449 \\
& \mathrm{x}_{246}{ }^{(0)}=367 \\
& \mathrm{x}_{328}{ }^{(0)}=285 \\
& \mathrm{x}_{410}{ }^{(0)}=203
\end{aligned}
$$

Langkah 2: Pemecahan dengan mengikuti persamaan linear. 


$$
\begin{gathered}
\mathrm{f}_{\mathrm{i}}^{(\mathrm{k})}=C_{i}\left(x_{i}{ }^{(k)}\right)+\alpha \sum_{j} P_{i j}\left(x_{i}{ }^{(k)}\right) f_{j}{ }^{(k)} \\
\mathrm{f}_{(0)}{ }^{(0)}=12.800 .000+0,96\left(0,05 \mathrm{f}_{(0)}{ }^{(0)}+0,05 \mathrm{f}_{(82)}{ }^{(0)}+\right. \\
0 \mathrm{f}_{(164)}{ }^{(0)}+0,24 \mathrm{f}_{(246)}{ }^{(0)}+0,19 \mathrm{f}_{(328)}{ }^{(0)}+ \\
0,47 \mathrm{f}_{(410)}{ }^{(0)}
\end{gathered}
$$$$
\mathrm{f}_{(82)}{ }^{(0)}=14.560 .538+0,96\left(0,05 \mathrm{f}_{(0)}{ }^{(0)}+0,05 \mathrm{f}_{(82)}{ }^{(0)}+\right.
$$$$
0 \mathrm{f}_{(164)}{ }^{(0)}+0,24 \mathrm{f}_{(246)}{ }^{(0)}+0,19 \mathrm{f}_{(328)}{ }^{(0)}+
$$$$
0,47 \mathrm{f}_{(410)}{ }^{(0)}
$$$$
\mathrm{f}_{(164)}{ }^{(0)}=16.321 .076+0,96\left(0,05 \mathrm{f}_{(0)}{ }^{(0)}+0,05 \mathrm{f}_{(82)}{ }^{(0)}+\right.
$$$$
0 \mathrm{f}_{(164)}{ }^{(0)}+0,24 \mathrm{f}_{(246)}{ }^{(0)}+0,19 \mathrm{f}_{(328)}{ }^{(0)}+
$$$$
0,47 \mathrm{f}_{(410)}{ }^{(0)}
$$$$
\mathrm{f}_{(246)}{ }^{(0)}=18.081 .615+0,96\left(0,05 \mathrm{f}_{(0)}{ }^{(0)}+0,05 \mathrm{f}_{(82)}{ }^{(0)}+\right.
$$$$
0 \mathrm{f}_{(164)}{ }^{(0)}+0,24 \mathrm{f}_{(246)}{ }^{(0)}+0,19 \mathrm{f}_{(328)}{ }^{(0)}+
$$$$
0,47 \mathrm{f}_{(410)}{ }^{(0)}
$$$$
\mathrm{f}_{(328)}{ }^{(0)}=19.842 .153+0,96\left(0,05 \mathrm{f}_{(0)}{ }^{(0)}+0,05 \mathrm{f}_{(82)}{ }^{(0)}+\right.
$$$$
0 \mathrm{f}_{(164)}{ }^{(0)}+0,24 \mathrm{f}_{(246)}{ }^{(0)}+0,19 \mathrm{f}_{(328)}{ }^{(0)}+
$$$$
0,47 \mathrm{f}_{(410)}{ }^{(0)}
$$$$
\mathrm{f}_{(410)}{ }^{(0)}=21.602 .692+0,96\left(0,05 \mathrm{f}_{(0)}{ }^{(0)}+0,05 \mathrm{f}_{(82)}{ }^{(0)}+\right.
$$$$
0 \mathrm{f}_{(164)}{ }^{(0)}+0,24 \mathrm{f}_{(246)}{ }^{(0)}+0,19 \mathrm{f}_{(328)}{ }^{(0)}+
$$$$
0,47 \mathrm{f}_{(410)}{ }^{(0)}
$$

Untuk menyelesaikan persamaan linear tersebut dengan menggunakan program bantuan mathcad. Adapun cara penyelesaiannya dapat dilihat pada lampiran, sedangkan hasil dari perhitungannya yaitu:

$$
\begin{aligned}
& \mathrm{f}_{(0)}{ }^{(0)}=561.400 .0 p 0 \\
& \mathrm{f}_{(82)}{ }^{(0)}=563.200 .000 \\
& \mathrm{f}_{(164)}{ }^{(0)}=564.900 .000 \\
& \mathrm{f}_{(246)}{ }^{(0)}=566.700 .000 \\
& \mathrm{f}_{(328)}{ }^{(0)}=568.400 .000 \\
& \mathrm{f}_{(410)}{ }^{(0)}=564.600 .000
\end{aligned}
$$

\section{Pada Bahan Baku Pipa}

Bila persediaan awalnya adalah 0 , maka persediaan yang harus dipesan adalah (203), (285), (367), (449), (531), (613). Ini artinya bahwa bila pada PT. Indomarine tidak mempunyai persediaan bahan bakú, maka perusahaan tersebut harus pesan atau diadakan penambahan persediaan bahan baku sebesar 203 sampai batas maksimal 613 .

Dan bila persediaannya adalah 82 maka bahan baku yang harus dipesan adalah sebesar (203), (285), (367), (449), (531).

Artinya bahwa bila pada perusahaan tersebut sudah punya persediaan bahan baku sebesar 82 maka penambahan yang harus dilakukan sebesar 203 sampai batas maxsimum 531. Kemudian seterusnya mengikuti tabel tingkat persediaan awal dan penambahan persediaan. Dan ini berarti bahwa semakin tinggi tingkat persediaan awal maka semakin sedikit penambahan persediaannya.

\section{Matrik Transisi dan Biaya}

Setelah diketahui nilai probabilitas transisi dan biayanya, maka nilai-nilai probabilitas tersebut ditransformasikan kedalam bentuk matrik transisi dengan mengambil biaya yang terkecil.

Dari matrik pertama tersebut, maka diketahui policy awal, yaitu :

$$
\begin{aligned}
\text { Policy awal }= & \mathrm{X}_{0}{ }^{(0)}=613 \\
& \mathrm{X}_{82}{ }^{(0)}=531 \\
& \mathrm{X}_{164}{ }^{(0)}=449 \\
& \mathrm{X}_{246}{ }^{(0)}=367 \\
& \mathrm{X}_{328}{ }^{(0)}=285 \\
& \mathrm{X}_{410}{ }^{(0)}=203
\end{aligned}
$$


Bila suatu perusahaan tersebut mempunyai persediaan awal 164 maka penambahan persediaan yang optimal adalah 449 .

Bila suatu perusahaan tersebut mempunyai persediaan awal 246 maka penambahan persediaan yang optimal adalah 367 .

Bila suatu perusahaan tersebut mempunyai persediaan awal 328 maka penambahan persediaan yang optimal adalah 285 .

Bila suatu perusahaan tersebut mempunyai persediaan awal 410 maka penambahan persediaan yang optimal adalah 203.

Dari policy awal yang ada pada iterasi pertama, didapatkan policy baru pada iterasi pertama yang ternyata sama dengan policy awal, yaitu :

$$
\begin{aligned}
& \text { Policy baru }= \mathrm{X}_{0}{ }^{(1)}=613 \\
& \mathrm{X}_{82}{ }^{(1)}=531 \\
& \mathrm{X}_{164}{ }^{(1)}=449 \\
& \mathrm{X}_{246}{ }^{(1)}=367 \\
& \mathrm{X}_{328}{ }^{(1)}=285 \\
& \mathrm{X}_{410}{ }^{(1)}=203
\end{aligned}
$$

Dengan adanya persamaan ini, dapat dikatakan bahwa policy tersebut telah optimal, sehingga tidak perlu untuk dilanjutkan pada iterasi berikutnya.

Sedangkan biaya persediaan minimum diperoleh dari langkah ketiga yaitu dengan mensubtitusikan biaya total pada persamaan

$\mathrm{f}_{\mathrm{i}}^{(\mathrm{k})}=C_{i}\left(x_{i}{ }^{(k)}\right)+\alpha \sum_{j} P_{i j}\left(x_{i}{ }^{(k)}\right) f_{j}{ }^{(k)} \quad$ sehingga diperoleh persamaan baru . Dengan bantuan program mathcad maka diperoleh biaya baru, biaya baru tersebut kemudian disubtitusikan ke persamaan linier sehingga didapat biaya terdiskonto yang merupakan biaya persediaan minimum, yaitu:

$$
\mathrm{f}_{(0)}{ }^{(1)}=555.772 .160
$$

$$
\begin{aligned}
& \mathrm{f}_{(82)}{ }^{(1)}=557.532 .698 \\
& \mathrm{f}_{(164)}{ }^{(1)}=559.293 .236 \\
& \mathrm{f}_{(246)}{ }^{(1)}=561.053 .775 \\
& \mathrm{f}_{(328)}{ }^{(1)}=585.438 .154 \\
& \mathrm{f}_{(410)}{ }^{(1)}=564.574 .852
\end{aligned}
$$

\section{E. KESIMPULAN}

Dari hasil pengolahan dan analisa data dapat disimpulkan bahwa:

1. Berdasarkan pada iterasi kedua dapat diketahui tingkat persediaan bahan baku yang optimal yaitu:

Bahan baku pipa

$$
\begin{aligned}
& \mathrm{x}_{0}{ }^{(1)}=613 \\
& \mathrm{x}_{82}{ }^{(1)}=531 \\
& \mathrm{x}_{164}{ }^{(1)}=449 \\
& \mathrm{x}_{246}{ }^{(1)}=367 \\
& \mathrm{x}_{328}{ }^{(1)}=285 \\
& \mathrm{x}_{410}{ }^{(1)}=203 \\
& \text { Menunjukkan bahwa apabila } \\
& \text { persediaan awal } 0 \text { maka persediaan } \\
& \text { yang optimal sebanyak } 613 \text { pcs. }
\end{aligned}
$$

2. Berdasarkan pada iterasi kedua dapat diketahui biaya persediaan minimum yang optimal, yaitu:

Bahan baku pipa

$$
\begin{aligned}
& \mathrm{f}_{(0)}{ }^{(1)}=555.772 .160 \\
& \mathrm{f}_{(82)}{ }^{(1)}=557.532 .698 \\
& \mathrm{f}_{(164)}{ }^{(1)}=559.293 .236 \\
& \mathrm{f}_{(246)}{ }^{(1)}=561.053 .775 \\
& \mathrm{f}_{(328)}{ }^{(1)}=585.438 .154 \\
& \mathrm{f}_{(410)}{ }^{(1)}=564.574 .852
\end{aligned}
$$


Sedangkan biaya persediaan minimum diperoleh dari langkah ketiga yaitu dengan mensubtitusikan biaya total pada persamaan

$$
\mathrm{f}_{\mathrm{i}}^{(\mathrm{k})}=C_{i}\left(x_{i}{ }^{(k)}\right)+\alpha \sum_{j} P_{i j}\left(x_{i}{ }^{(k)}\right) f_{j}{ }^{(k)}
$$

sehingga diperoleh persamaan baru . Dengan bantuan program mathcad maka diperoleh biaya baru, biaya baru tersebut kemudian disubtitusikan ke persamaan linier sehingga didapat biaya terdiskonto yang merupakan biaya persediaan minimum

Ini artinya bahwa, bila suatu perusahaan tersebut mempunyai persediaan awal 0 maka penambahan persediaan yang optimal adalah 613

Bila suatu perusahaan tersebut mempunyai persediaan awal 82 maka penambahan persediaan yang optimal adalah 531 .

Bila suatu perusahaan tersebut mempunyai persediaan awal 164 maka penambahan persediaan yang optimal adalah 449 .

Bila suatu perusahaan tersebut mempunyai persediaan awal 246 maka penambahan persediaan yang optimal adalah 367 .

Bila suatu perusahaan tersebut mempunyai persediaan awal 328 maka penambahan persediaan yang optimal adalah 285 .

Bila suatu perusahaan tersebut mempunyai persediaan awal 410 maka penambahan persediaan yang optimal adalah 203.

Menunjukkan bahwa apabila persediaan awal 0 maka persediaan yang optimal sebanyak 613 pcs

\section{DAFTAR PUSTAKA}

Ahyari,A, Pengendalian Produksi I, Edisi 4, BPFE Yogyakarta, 1986.

Assauri,Sofjan, Manajemen Produksi dan Operasi, Edisi 4, LPFE Universitas Indonesia, 1969.

Biegel, John E. 1992, Pengendalian Produksi: Suatu Pendekatan Kuantitatif, Akademika Pressindo, Jakarta

Daellenbach,H.A,George,J.A, Introduction to Operation Research Techniques, University of Canterbury, Christchurch, New Zeland, 1978.

Hamdy A. Taha. 1996. Riset Operasi Jilid 2, Penerbit Binarupa Aksara, Jakarta.

Hines, William W. 1990 Probabilitas Dan Statistik Dalam Ilmu Rekayasa dan Manajemen, Edisi Kedua, Penerbit UI, Jakarta.

P Siagian, Penelitian Operasional Dan Riset, UII Press, 1987.

Subagyo, Pengestu, Dasar-Dasar Operationts Research, Edisi 2, BPFE Yogyakarta, 1995.

Sulistyati, Aplikasi Markov Chain Dalam Menentukan Tingkat Persediaan Produk Yang Optimal Pada Perusahaan Indah Cemerlang, ITN Malang, 2000.

Sudjana, Metode Statistika, Edisi 6, TARSITO Bandung, 1996.

Ross, Sheldon M.1985 Introduction to probability Models, California

Thims, Henk C. 1995, Stochastic Models, Amsterdam. 
Tjutju T. Dimyati, Ahmad Dimyati, 1985 Operations Research, Model-model Pengambilan Keputusan, edisi Kedua Penerbit Sinar Baru Algesindo, Bandung.

Taha,Hamdy A, Riset Operasi, Jilid 2, Edisi 5, Binapura Aksara, Jakarta Barat, 1997.

Djarwanto, Ps., Drs., Statistik Nonparametrik, Edisi 3, BPFE Yogyakarta, Desember 1999.

Lewis, E.E., Introduction To Reliability Engineering, John Wiley \& Sons, Canada 1987.

Leemis, Lawrence M., Reliability : Probabilistic Models And Statistical Methods, Prentice Hall, New Jersey, 1995.

Rammakumar, R., Engineering Reliability: Fundamentals And Aplication, Prentice Hall, New Jersey, 1993

Smith, Charles O., Introduction To Reliability In Design, McGraw-Hill, New York, 1976.

Starr, Martin K., dan Miller, David W., Inventory Control : Theory And Practice, Prentice Hall, New York, 1981.

Freddy Rangkuti., Manajemen Persediaan: Aplikasi di Bidang Bisnis, Rajawali Pers, Jakarta, 2004 